[Supporting Information]

\title{
Dielectrophoresis Field Flow Fractionation of Single-Walled Carbon
}

\section{Nanotubes}

Haiqing Peng, Noe T. Alvarez, Carter Kitttrell, Robert H. Hauge and

Howard K. Schmidt *

Carbon Nanotechnology Laboratory,

Richard E. Smalley Institute for Nanoscale Science and Technology,

Department of Chemistry,

Rice University, 6100 South Main Street, Houston, Texas 77005, USA

- $\quad$ Ref. (15) Maeda, Y.; Kimura, S.-i.; Kanda, M.; Hirashima, Y.; Hasegawa, T.; Wakahara, T.; Lian, Y.; Nakahodo, T.; Tsuchiya, T.; Akasaka, T.; Lu, J.; Zhang, X.; Gao, Y.; Yu, Y.; Nagase, S.;

Kazaoui, S.; Minami, N.; Shimizu, T.; Tokumoto, H.; Saito, R. Journal of American Chemical Society 2005; 127(29); 10287-10290.

- $\quad$ Dielectrophoresis chamber geometry:

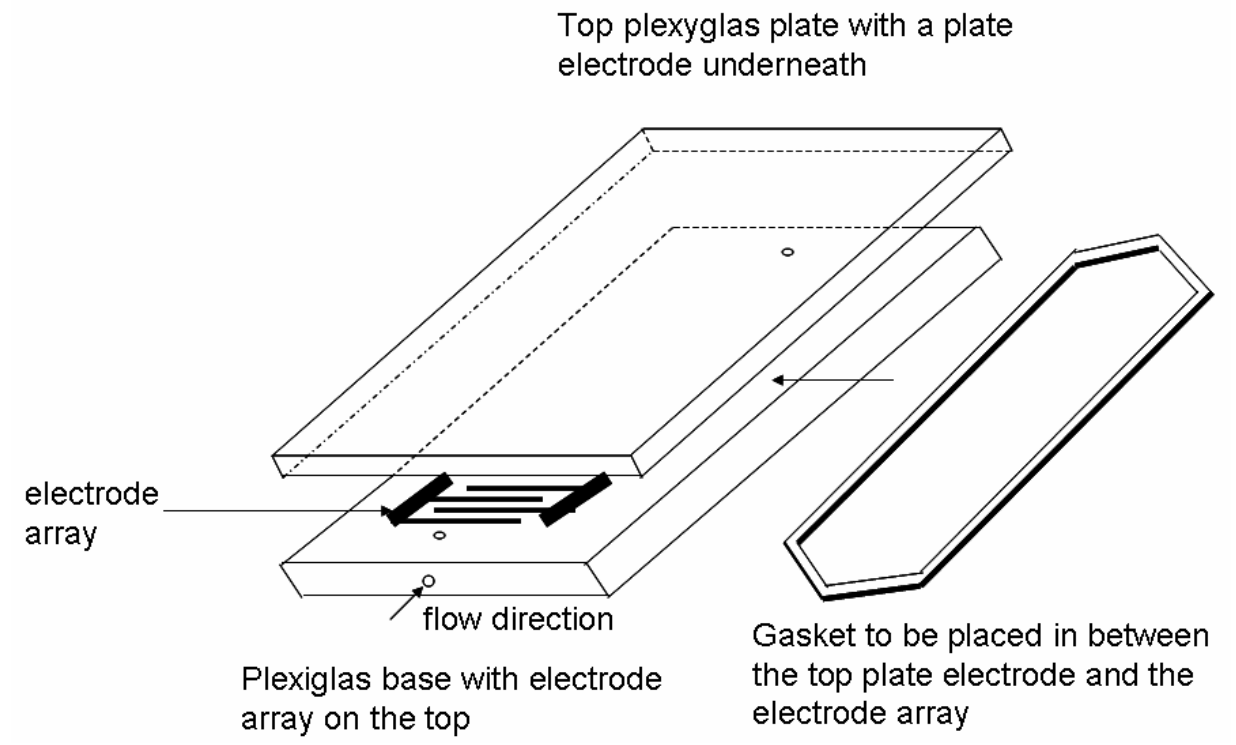

